\title{
Utilização de tecnologias no trabalho com grupos de diabéticos e hipertensos na Saúde da Família
}

\author{
Use of technologies working with groups of diabetic \\ and hypertensive individuals in Family $\mathrm{H}$ ealth
}

M aria Teresinha de Oliveira Fernandes ${ }^{1}$

Líliam Barbosa Silva²

Sônia M aria Soares ${ }^{2}$

${ }^{1}$ Secretaria M unicipal de Saúde, Prefeitura deBelo Horizonte, M inas Gerais. Av. Professor Alfredo Balena

190, Santa Efigênia. 30130-

100 Belo Horizonte M G.

mtofernandes@gmail.com

${ }^{2} \mathrm{Núcleo} \mathrm{deEstudose}$

Pesquisas em Cuidado e

Desenvolvimento Humano,

Escola deEnfermagem,

UniversidadeFederal de

Minas Gerais.
Abstract This study aimed to reveal the technologies of working with groups of diabetic and hypertensive peoples in the perspective of Family $\mathrm{H}$ ealth professionals. It is a qualitative research, carried through in the primary care units of a sanitary district of Belo $\mathrm{H}$ orizonte, M inas G erais State, Brazil. The data had been analyzed according to the technique of content analysis proposed by Bardin. The study showed that the groups coordinators need a theoretical foundation and that exist the incorporation of technologies that embrace the context of a practice sometimes exists little criticized and differentiated and others wrapped up by diversified elements of the care. In this direction, sensitization for the necessity of thetechnologies that allows humanized attitudes, not only in the perspective of the coordinators, but also in the users', as the look at the diabetic and hypertensive peoples goes beyond the monitoring related to the use of medicines.

Key words Group structure, M ethods, Diabetes mellitus, Hypertension, Family $\mathrm{H}$ ealth Program
Resumo Este estudo objetivou desvelar as tecnologias detrabalho com gruposjunto às pessoas com diabetes ehi pertensão na perspectiva dos profissionais da Saúde da Família. Trata-se de pesquisa qualitativa, realizada nasunidades básicas desaúde de um distrito sanitário do M unicípio de Belo H orizonte (M G). Os dados foram analisados segundo a técnica de análise de conteúdo proposta por Bardin. 0 estudo mostrou que os coordenadores de grupos necessitam de aporte teórico e que existe a incorporação de tecnologias que abrangem o contexto de uma prática ora pouco criticada e diferenciada e ora envolta por elementos diversificados do cuidado. N esse sentido, espera-se sensibilização para a necessidade da mobilização de tecnologias que possibilitem atitudes humanizadoras, tanto na perspectiva dos coordenadores quanto dos usuários, vez queo olhar para a pessoa com diabetes e hipertensão vai além das vigilâncias relacionadas ao uso dos medicamentos.

Palavras-chave Estrutura de grupo, M étodos, Diabetes mellitus, Hipertensão, Programa Saúde da Família 


\section{Introdução}

As tecnologias de trabalho em saúde apresentam-se numa concepção ampliada, a partir do conceito proposto por $M$ erhy $^{1}$, em tecnologias leves, leve duras eduras. As tecnologias leves são aquelas que remetem a relações entre sujeitos, estabelecidas no trabal ho vivo em ato, ou seja, no momento em que o trabalho está sendo produzido. As tecnologias leve-duras referem-se à aplicação de conhecimentos e saberes constituídos e ao modo singular como cada profissional aplica este conhecimento para produzir o cuidado. Já as tecnologias duras compreendem aquelas inscritas nos instrumentos, estruturadas para elaborar certos produtos em saúde ${ }^{1,2}$.

N esse sentido, a utilização detecnologias para viabilizar o cuidado no trabalho com grupos de pessoas com diabetes mellitus e hipertensão arterial é hoje uma prática recorrente nas equipes de Saúde da Família, o que tem chamado a atenção, visto queo emprego inadequado dessas tecnologias pode diminuir, ou, até mesmo, inviabilizar a produtividade do grupo.

O ser humano, ao adoecer, se vê repentinamente frente a várias mudanças de hábitos de vida. Desse modo, cabe à equipe de Saúde da Família identificar e propor ações relacionadas à patologia, ao tratamento, assim como aos sentimentos, às expectativas e, consequentemente, à segurança emocional que também fica comprometida ${ }^{3}$. Compreende-se, assim, que para efetivar essas ações, é necessário promover a integração das tecnologias utilizadas no trabalho com grupo, quais sejam, as tecnologias leves, leveduras e duras, pois a conformação das três gera qualidade, ao favorecer aos participantes algo muito além da representação física da doença: 0 aprender a cuidar/cuidar-se ${ }^{2,3}$.

Lembra-seaqui quea Saúde da Famíliaéuma estratégia de assistência à saúde, socialmentesensível, quevisa identificar os principais problemas de saúdee as situações de risco que acometem as famílias, de modo a proporcionar melhorias na qualidade de vida da população ${ }^{4}$. Permite otimizar o desenvolvimento do trabalho com grupos para o enfrentamento dos agravos de saúde aí identificados, fortalecendo as ações de prevenção da doença, promoção e recuperação da saúde, de forma integral e contínua.

A partir da implementação dessa estratégia, o acompanhamento às pessoas tem ocorrido muitas vezes em grupos, formados pela semelhança de seus membros do ponto de vista da patologia, gerado pelo aumento dessa demanda. Para ilus- trar, em Belo Horizonte (MG), somente no Distrito Sanitário Pampulha, no ano de 2005, foram realizados 1.131 atendimentos em grupo desenvolvidos por enfermeiros, auxiliares de enfermagem emédicos ${ }^{5}$. Observa-se, entretanto, quenem sempre os profissionais de saúde estão preparados para assumir a coordenação desses grupos, na medida em que esta prática exige atributos e habilidades, imprescindíveis para a interpretação dos fenômenos grupais ${ }^{6,7}$, muito além de cuidar da doença e promover saúde nos grupos identificados a partir do diagnóstico médico.

Entre 1995 e2002, a cidade de Belo H orizonte vivenciou a implementação do SistemaÚ nico de Saúde, sendo a primeira capital do país habilitada em gestão semiplena. N esse período, uma das várias atividades realizadas na rede eram os grupos operativos, cujo enfoque era o planejamento familiar, prevenção do câncer de colo de útero e da mama, acompanhamento e controle de diabetesehipertensão, puericultura eorientação para mães das crianças inscritas no Programa de Pre venção e Combate à Desnutrição.

As dificuldades no processo de desenvolvimento desse trabal ho eram inusitadas, destacando a grande demanda, infraestrutura inadequada, falta de material audiovisual, panfletos informativos e educativos, enfim, falta de apoio logístico.

Preconiza-se que o trabal ho com grupos nas unidades básicas seja realizado por uma equipe multiprofissional, o que tem exigido dos profissionais de saúde a busca e a apropriação de tecnologias para viabilizar a aprendizagem de forma criativa e o manejo do tratamento pelos sujeitos, tais como teatro, musicoterapia, dinâmicas degrupo, ludoterapia, técnicas derelaxamento e de automassagem, dentre outros.

Nesteestudo, o conceito detecnologia no trabalho com grupos é empregado na mesma perspectiva descrita por M erhy ${ }^{1}$, que compreendenão somente a aplicação deum conjunto de conhecimentos e uso de equipamentos, mas também de vários outros elementos, que, inseridos em uma situação de grupo, incluem o acolhimento, diálogo com os membros, escuta, vínculo, integração e interesse, o que favorece a consecução dos objetivos do grupo: coesão, interação e aprendizagem grupal. Ao pensar no trabalho em saúde, reconhece-se a singularidade desse, que se produz em ato, na subjetividade dos sujeitos envolvidos, ea importância de se conhecer as tecnologias que viabilizam esse processo produtivo.

Justifica-se a realização desse estudo, considerando que pesquisas que discutem a utilização 
de tecnologias no trabal ho com grupos são ainda pouco exploradas, havendo a necessidade de apreendêlas criticamente no contexto da Saúde da Família.

A partir dessas considerações, tem-se como objetivo desvelar as tecnologias utilizadas pelos profissionais de saúde das equipes de Saúde da Família no trabal ho com grupos de pessoas com diabetes mellitus e hipertensão arterial.

\section{Abordagem metodológica}

Trata-se de uma pesquisa qualitativa. Esta modalidadedeestudo permitiu conhecer o universo de significados, crenças, valores eatitudesna perspectiva dos profissionais da Saúde da Família frente às tecnologias utilizadas para o manejo do grupo.

Os sujeitos da pesquisa foram dezenove profissionais que integravam as equipes de Saúde da Família, atuando como coordenadores de grupos junto às pessoas com diabetes mellitus e hipertensão arterial em Unidades Básicas de Saúde do Distrito Sanitário Pampulha de Belo Horizonte (MG). Dentre eles, três técnicos de enfermagem (enfermagem de nível médio - ENM), dez enfermeiros, quatro médicos, uma assistente social e uma docente de fisioterapia.

Os critérios de inclusão dos informantes foram: (1) equipes completas, compostas de um médico, um enfermeiro, dois profissionais de enfermagem do nível médio; (2) equipes em que as atividades de grupos estavam voltadas para pessoas com diabetes e hipertensão; (3) profissionais do nível superior e médio que coordenavam grupos e (4) profissionais que aceitaram colaborar com a pesquisa. Os critérios de exclusão consistiram em: (1) equipes incompletas; (2) equipes que não desenvolviam atividades degrupo para pessoas com diabetes e hipertensão e (3) equipes dos profissionais que não se interessaram em colaborar com a pesquisa. Para dois informantes, esses critérios não foram seguidos rigorosamente, como é o caso da participação da assistente social e da docente de fisioterapia. Estas são referências no trabalho com grupos evidenciadas tanto nas entrevistas como pelo próprio gerente local e equipes de Saúde da Família; assim, optou-se por incluí-las no estudo.

As informações foram coletadas de junho a novembro de 2006, por meio da observação participante dos grupos e entrevista aberta com os coordenadores de grupos, após esclarecimento da proposta e assinatura do termo de consentimento livre e esclarecido. As entrevistas foram individuais, agendadas previamente e realizadas nas Unidades Básicas de Saúde, com duração média de quinze minutos, no horário de escolha dos informantes, de forma que fosse garantida a privacidade de cada um. As entrevistas foram gravadas em fita cassete, transcritas na íntegra e validadas pelos informantes. A questão norteadora foi "Fale como é a sua experiência com os grupos, considerando as tecnologias utilizadas para viabilizar o cuidado no grupo".

Durante a coleta de dados, utilizou-se o caderno de campo, preparado em duas colunas verticais: uma para registro de informações a respeito das condições em que a entrevista e a observação foram realizadas e outras anotações pertinentes e a segunda para notas e considerações da pesquisadora.

Para encerrar a coleta de dados, foi utilizado o critério de saturação de dados, o qual, na pesquisa qualitativa, refere-se ao momento em que o pesquisador não consegue mais obter novas informações significativas sobre o fenômeno estudado ${ }^{8}$.

Os dados foram analisados segundo a técnica de análise de conteúdo proposta por Bardin ${ }^{9}$, acontecendo de forma simultânea à coleta de dados. A pós exaustivas leituras, os depoimentos foram analisados, codificados e categorizados, resultando nos seguintes núcleos temáticos: (1) estratégias do trabalho com grupos de pessoas com diabetes mellitus e hipertensão arterial e (2) tecnologia do trabalho com grupos na perspectiva transcultural. Para aten der aos objetivos desse estudo, estes núcleos temáticos foram reordenados segundo a definição ampliada de tecnologia proposta por Merhy².

Ressalta-se que a coleta de dados teve início após o consentimento formal das instituições e aprovação dos Comitês de Ética e Pesquisa da UniversidadeFederal de M inas Gerais eda Secretaria M unicipal de Saúde de Belo H orizonte, em consonância à Resolução n 196 de 10 de outubro de 1996, do Conselho Nacional de Saúde ${ }^{10}$.

\section{Resultados ediscussão}

Nesse estudo, identificaram-se tecnologias leves, leve-duras e duras, as quais foram apontadas como fundamentais para otimizar o cuidado no grupo e encontram-se descritas a seguir. 


\section{Tecnologias leves}

As falas que evidenciaram as tecnologias leves utilizadas nos grupos foram acolhimento, vínculo e busca de autonomia dos sujeitos, por meio de um diálogo aberto e uma escuta qualificada, deslocando o foco da produção de procedimentos para a produção de cuidados:

“E eles falam muito pra gente. Como já criou aquele vínculo, aquela afinidade, eles têm liberdade de falar com a gente que 'eu só tenho isso para comer, o quê que eu posso fazer?'" (E-ENM)

Sabe-se que as tecnologias leves condensam em si as relações de interação e subjetividade, o que dinamiza o processo de interação do cliente no grupo, de modo a facilitar a aprendizagem. Ao se privilegiar o diálogo, a escuta e o envolvimento com a queixa do outro, tem-se um acoIhimento resolutivo, sendo imperiosa a corresponsabilização entre profissionais de saúde e cliente na procura pelo melhor cuidado ${ }^{11}$.

Lembra-se que o cuidado é mediado pelo contato, pelo afeto, pelo reconhecimento do outro como ser único, que necessita ser respeitado no seu meio social, pois diverge no seu conhecimento de práticas à saúde e nos modos de ver e viver a vida. Contribuem, assim, para um novo olhar sobre o "fazer" em saúde, rompendo com o processo centrado nalógica instrumental eprescritiva de produção de saúde. Vale destacar quea Estratégia Saúde da Família aposta no "estabele cimento de vínculos e a criação delaços de compromisso e de co-responsabilidade entre profissionais de saúde e a população"12.

O vínculo, por sua vez, écompreendido como uma estrutura complexa, que tem um caráter social e que envolve uma inter-relação entre sujeitos e objetos por meio dos processos de comunicação e aprendizagem ${ }^{13}$.

N esse sentido, o processo comunicativo no grupo se dá por meio do diálogo, da escuta sensível e das conversas informais, de modo que os participantes interagem de modo a colocar-se à disposição do outro e a atribuir valor às inquietações e questionamentos emergentes: "A gente conversa muito, não fica só naquelas coisas assim, falando só de hipertenso [doença]. A gente aproveita o grupo e conversa". (E-ENM)

O bserva-se, na fala acima, uma tendência à ruptura com as estratégias comunicacionais informativas, como palestras, em prol de uma comunicação quevaloriza o diálogo. Aqui o cliente é reconhecido como sujeito detentor de um saber que, embora diverso do saber técnico-científico, não é deslegitimado pelo coordenador, e, enquanto interlocutor, encontra-se em contínua troca deconhecimentos, emoções einformações. Ao intercambiar os saberes científico e popular, o coordenador permite a maior aproximação de práticas que contribuem para a superação do modelo individualista e fragmentado de assistência, ainda predominante nos dias atuais ${ }^{14}$.

Campos $^{15}$ refere-se à importância de se resgatar a fala e a escuta nos espaços das práticas de saúde, contrapondo-se ao clássico padrão de intervenção terapêutico. Nesse sentido, a renovação dos modos de comunicação entre coordenador e demais membros do grupo, em que se privilegia a escuta de uns pelos outros, possibilita a diminuição da dependência dos participantes à figura do coordenador, o que promove crescimento individual e grupal.

A comunicação consistena capacidade depôr em comum o que sabem ou vivem determinadas pessoas. As mensagens enviadas e recebidas influenciam o comportamento dos sujeitos envolvidos, de modo que estes se encontram constantemente envolvidospor um campo interacional ${ }^{16}$. Além disso, trata-se delugar privilegiado no qual se expressam os transtornos e dificuldades do grupo para enfrentar a tarefa. Assim, quanto melhor a comunicação, melhor será o funcionamento grupal, uma vez que a coesão de um grupo, o comportamento cooperativo e as decisões coletivas dependem em grande parte da comunicação existente, tanto na sua natureza quanto na sua amplitude, o que demonstra um respeito ao contexto cultural do grupo ${ }^{13,17}$.

Para se ter uma boa comunicação interpessoal, é necessário estabelecer uma atitu de de diálogo, o que implica ser capaz de ouvir o outro antes de responder, de analisar e discutir um problema ou uma situação antes de julgar ou dar opinião e ser capaz de questionar-se, retificando as próprias posições ou pontos de vista, quando o outro ou o grupo mostra as insuficiências do seu pensamento próprio ${ }^{17}$. Para tanto, destacase o papel do coordenador de grupo, que tem por função ajudar o grupo a sair dos estereótipos, do já conhecido, efacilitar o diálogo entreos membros, de modo a não centralizar a fala do grupo em si ${ }^{18}$.

Ainda éinteressante destacar que o grupo tem proporcionado aproximações com a cultura do usuário, em que o profissional começa a usar uma linguagem mais acessível, menos técnica, de forma a socializar as informações sobre tratamento sem perder o conteúdo, conforme é relatado por uma enfermeira: "A gente coloca uma linguagem bem simples, bem próxima daquilo que 
eles [os clientes] podem estar acompanhando epercebendo. A téo médico está começando a falar mais fácil, a sentar no meio deles, não tem mais aquela postura de longe. A gente senta no chão, entra no meio deles. Então isso facilitou uma intimidade muito grande com o médico". ( $M$-enfermeira)

A esserespeito, enfatiza-se quea validação da comunicação intragrupo pressupõe que seus membros tenham conseguido, ao se integrarem, adotar uma linguagem comum, reconhecer símbolos e códigos que thes são próprios ${ }^{19}$. Ainda, esse autor sugere que, uma vez estabelecidas relações humanas igualitárias entre os membros e o coordenador do grupo, a comunicação terá condições de ser aberta e circular. Caso o contrário, não haverá a compreensão de sinais entre os sujeitos, inviabilizando o processo comunicativo e, por conseguinte, comprometendo o alcance dos objetivos do grupo 20 .

Outra potencial tecnologia leve utilizada pelos coordenadores refere-se às dinâmicas de grupo, que permitem o desenvolvimento intragrupal e aprimoramento das relações entre coordenadores e demais membros; entretanto, observa-se que as mesmas são empregadas com o significado de brincadeiras, de pouco valor agregado e pouco exploradas: "Sempre alguma brincadeira. Ou aquela do balão, põe a pergunta dentro do balão, fura o balão, tem uma fraselá quea gente pergunta o que é, ou a gente canta uma música, vai batendo palma e na hora que pára a música, ele [o cliente] responde". (T-enfermeira)

Pelo exposto, o significado de dinâmica para esses informantes remete a formas facilitadoras para abordar temas relacionados, num primeiro plano, à doença e tratamento e, num segundo, às relações interpessoais, implícita elimitadamente trabalhadas, pois não há exploração de seus resultados. Dessa forma, é utilizada de forma simplista, negligenciando etapas na execução de atividades vinculadas à dinâmica grupal21.

Alguns autores alertam quanto à banalização dessa tecnologia, não sendo raro às vezes em que são confundidas com os fins da ação de grupo propriamente ditos, estereotipando o campo de pesquisas da dinâmica de grupos, o que compromete a avaliação das características dos processos grupais em progresso, $0^{6,22,23}$.

Sabe-se que a mesma compreende as interações eprocessos gerados no interior do grupo, consequenteàsua existência, epodeser entendida como teoria, técnica ou modo deatuar em grupo. Como técnica, auxilia com grande eficácia o autoconhecimento a partir de uma situação psicossocial, o que pode ajudar na resolução de possíveis problemas de dinâmica ${ }^{17}$. Para tanto, a técnica de grupo deve ser empregada de forma contextualizada e vinculada às características processuais dos grupos em que é aplicada, para não confrontar ao que o grupo está sentindo e vivenciando 23,24 .

A não observância desse aspecto pode levar à cristalização da situação atual, o que inibe a maturidade grupal. Se não houver pertinência entre o material processado eo objetivo traçado, o grupo vivencia experiências que podem até agregar um crescimento do sujeito, mas não contribuem para 0 alcance dos objetivos estabelecidos ${ }^{24}$.

Dessa forma, adverte-se sobre a necessidade de o coordenador utilizar esses recursos com habilidade e destreza, refletindo sobre sua adequação ao contexto em que serão empregados, assim como de seus participantes assumirem uma atitude madura e produtiva ${ }^{17,21}$.

Valelembrar que esse instrumental possibilita desencadear nos grupos experiências valiosas, levando-os a conscientizar-se de sua dinâmica interna e a desenvolver melhores padrões de comunicação e cooperação. Existe, no entanto, sua contrapartida, uma vez que, se, de um lado, essas técnicas podem constituir-se em instrumento conscientizador e libertador, de outro, poderão manipular e dominar ${ }^{25}$.

A dinâmica utilizada, portanto, não parece ser concebida como tecnologia para a produtividade do grupo e promover o desenvolvimento da autonomia do sujeito no ato da produção do cuidado.

\section{Tecnologias leve-duras}

Algunsinformantes mobilizam conhecimentos técnico-científicos específicos para o manejo grupal, classificado como tecnologia leve-dura, permitindo operar sobre recursos na realização definalidades perseguidas e postas para este processo produtivo: "Para recurso, a gente usa mais o quea gente aprendeu durante 0 curso de especialização de Saúde da Família [ refere-se ao conhecimento adquirido durante a disciplina sobre trabalho com grupos, ministrada durante o curso]". (R-enfermeira)

É importante lembrar quea incorporação de conhecimento teórico só terá valor sehouver reciprocidade com a prática grupal. Salienta-seque a técnica sem uma fundamentação teórica pode levar a um agir intuitivo ou passional2 ${ }^{26}$.

As tecnologias leve-duras também foram representadas por vários recursos pedagógicos, os quais se desvelaram em seu aspecto relacional ou, de forma concreta, a partir de recursos visuais, ligados a uma determinada temática. 
Como recurso pedagógico, al gunsinformantes mencionaram o uso de álbuns seriados, vídeos educativos, panfletos, cartazes ilustrativos e outros para estimular a discussão entre os envolvidos, o que é confirmado pelos trechos: “No [caso do] hipertenso e diabético, a gente utiliza cartazes que a gente mesmo faz, panfletos que são distribuídos na rede". (R-enfermeiro);

"Tinha um ou outro folder aí que a gente utilizou. No caso do diabetes, tem um pequeno mostruário, com algumas imagens, a gente leva imagens que são cartazes ou até mesmo textos sobre 0 tema". (B-médico);

"Fita de vídeo eu já passei para eles sobre a história [de Godofredo, um portador de neuropatia diabética]". (A-médica)

Algumas autoras afirmam que estas técnicas funcionam como estimuladores da manifestação e da reciprocidade ou troca de experiências entre os membros do grupo, as quais são refletidas, localizando o problema em si, sua historicidade e 0 seu contexto pessoal e social27. Entretanto, ressalta-se que, não raro às vezes, esses recursos não são elaborados pelo próprio município ou pela equipe de saúdee, por conseguinte, o conteúdo dos recursos adotados pode refletir um distanciamento entre a situação do grupo e aquela apresentada no material, o que pode dificultar o interessee o envolvimento das pessoas em torno da tarefa proposta ${ }^{28}$.

N esse sentido, os profissionais de saúde podem, a partir da participação do grupo na escoIha das temáticas a serem abordadas no grupo, propor a construção de seu próprio material educativo, que reflita diretamente a situação do grupo como, por exemplo, o uso de fotos ou imagens que ilustrem a própria comunidade ${ }^{29}$.

Ressalta-se, contudo, que para a realização da atividade grupal, não é necessário o uso de vídeos e de outros materiais sofisticados, até mesmo porque nem sempre se encontram à disposição das equipes de Saúde da Família. N essa perspectiva, al guns informantes remeteram-seao uso de folhetins de supermercados, jornais, revistas, garrafas pet, listas telefônicas velhas, meia calça em desuso, cabo de vassoura, como materiais sem valor financeiro e até mesmo descartáveis, mas alternativos para o grupo no sentido de efetivar o cuidado: "Já ensinei os usuários a fazer. Colocar bacia em casa com bolinha de gude, para assistir televisão, fazer um bordado. Ela vai por o pé para melhorar a circulação, evitar pé diabético; toquinho com cabo de vassoura, também, colocar no chão, lixado para não ter farpinha, dá para fazer também e por o pé". (J-enfermeira)
“Eles precisavam deobjetos pra fazer esses exercícios [referindo-se à Academia do Lar]. M as precisavam de pesinhos pro braço. A gentefez com uma garrafinha de coca-cola, de refrigerante de $500 \mathrm{ml}$. Nós enchíamos ou de areia ou de água, qualquer coisa pra virar peso de meio quilo pra cada braço. A té o step a gente construiu com lista telefônica grossa, antiga, que ninguém usava mais. A gente amarrou as listas telefônicas, aí tinha um step pra trabalhar subida edescida". (L-enfermeira)

Aqui, materiais descartáveis assumem lugar de destaque nos grupos, transformando-se em recursos para viabilizar o cuidado. Dessa forma, a criatividadee o envolvimento entreo coordenador e os demais membros do grupo podem ser fatores determinantes no sucesso das atividades com grupos ${ }^{30}$. Coordenadores criativos, capazes de criar algo original, único e pessoal ${ }^{31}$, o que facilita o processo de aprendizagem. No contexto do grupo, esses simples materiais foram ressignificados para apoiar e dar suporte às pessoas que desejam adotar hábitos de vida mais saudáveis.

A esse respeito, importante lembrar que a utilização de tais materiais pode mobilizar conteúdos primitivos de imagens internas e subjetivas, de modo que o coordenador de grupo deve estar habilitado para lidar com os conteúdos inconscientes dos participantes e da fantasia grupal, bem como permitir que as emoções fluam como processo terapêutic ${ }^{32}$.

Um aspecto a ser considerado quando do uso de qualquer material pedagógico refere-se à sua adequação, conforme as limitações físicas, psicológicas e sociais dos participantes. Esse aspecto também écontemplado por al guns informantes: "São pessoas quetem ou dificuldadevisual pela idade, ou pela doença, ou pela intelectualidade. São pessoas com baixo nível de escolaridade. Então, eu tenho que trabalhar de uma maneira pra que eles realmente entendam. $\mathrm{N}$ ão adianta eu fazer cartaz com letra pequena, escrito lá um monte de coisas, que aquilo ali não vai servir de nada". (L-enfermeira)

Assim, esses instrumentos devem ser potencialmente significativos para o aprendiz, vez que a aprendizagem significativa éindividual ${ }^{33}$. D evese relacionar o conteúdo a ser transmitido com aquilo que o educando sabe, permitindo queeste use sua própria linguagem e expresse sua visão de mundo.

Outros recursos utilizados pelos coordenadores referem-se aos próprios elementos disponíveis no ambiente de trabalho: "A gente utiliza os elementos do ambiente. Aqui fora é um pátio, aberto, e tem um pátio coberto que a gente utiliza 
quando a gente tem chuva. A gente utiliza os de graus, o degrau da entradinha para fazer alguma atividade de membros inferiores". (V-docente de fisioterapia)

Dessa forma, a promoção da atividade física e da nutrição saudável possibilita rever crençase valores em seus contextos de vida, que cada vez mais são limitados pela influência dos fatores econômicos, políticos, sociais, culturais e a visão de mundo das pessoas.

\section{Tecnologias duras}

Outros recursos utilizados pelos informantes referem-se aos equipamentos, tais como, glicosímetro, aparelho de pressão e balanças, que, tradicionalmente, estão no centro das representações acerca das necessidades de saúde, caracterizados como tecnologias duras, na medida em que se conformam em saberes e fazeres bem estruturados e materializados, já acabados e prontos: “A genteleva o aparel ho de pressão e o esfigmo, a balança, já levamostambém". (B-médica)

Esse achado é corroborado por outro estudo que, ao buscar compreender o significado da vivência no grupo por pessoas com diabetes mellitus, identificou que os procedimentos demedida depeso, glicemia epressão arterial realizadosnos grupos eram como um ritual que cumpre com a função, retratando, de maneira simbólica, valores essenciais e orientações culturais, reafirmando, assim, a condição de ser diabético e as necessidades específicas e inerentes a esta condição ${ }^{34}$.

Também são utilizados formulários para re gistro de atividades da prática de grupo: "[U samos] agenda. Cartão de hipertenso. [As guias de] referência e atestado de comparecimento são os impressos que a gente usa com mais frequência. [ Impresso das atividades direcionadas] de grupo. A gente preenche. A gente coloca todasasatividades que foram abordadas, o que nós abordamos em termos de orientação, qual a dinâmica que foi feita equem participou". (R-enfermeira)

Para que esses instrumentos sejam potencializadores da aprendizagem no grupo, os mesmos devem ser permeados por aspectos relacionais, pois a simples capacitação técnica dos profissionais não deve ser compreendida como a simples aquisição de instrumentos e técnicas rígidos que possam ser utilizados, de forma gene ralizada, em suas ações educativas ${ }^{29}$.

A partir desses achados, observa-se que a busca dos objetivos do trabalho com os grupos vem permeada pela tecnologia baseada em conhecimentos técnicos, dinâmicas, além do em- prego de fôlderes, cartazes, álbuns seriados e outros, em queo aspecto relacional éfundamental para estabelecer o conhecimento bilateral, compartilhando as culturas e o cuidar.

Tais tecnologias, quando bem utilizadas, podem ajudar a desvelar aspectos implícitos do processo grupal, pois possibilitam esclarecer as pautas estereotipadas que dificultam a aprendizagem e a comunicação no grupo ${ }^{13}$.

Quando as tecnologias são utilizadas inadequadamente, o próprio movimento do grupo fornecerá alguns indicativos de que o encontro não está sendo operativo, ao contrário, está a serviço da reprodução do velho modelo assistencial. 0 mau aproveitamento do grupo poderá ser constatado pelo término que se dá pelo esvaziamento, atrasos frequentes dos participantes, o entrar e sair a toda a hora, a dificuldade de encerrar o encontro, os participantes podem demonstrar-se desinteressados pelo conteúdo abordado e resistentes em participar das discussões dos temas, se dispersando dos assuntos de vários modos, além de apresentarem-se ansiosos para o término das reuniões ${ }^{35,36}$.

Ressalta-se que esta inadequação pode ocorrer, até mesmo, quando os objetivos ainda não estão claros para o profissional durante a escoIha da técnica a ser utilizada no grupo, fato este constatado nesse estudo.

Ao levar em conta todos os aspectos levantadosnesse estudo, entende-se quea utilização dessas tecnologias deve estar embasada em conhecimento científico específico sobre 0 assunto, assim como estar contextualizada segundo a situação de cada grupo, mostrando sua pertinência e viabilidade ao trabalho que se propõe organizar. Dessa forma, a cultura, saberes e práticas têm peso equivalente aos modos de cuidar. Lançar mão dessas tecnologias éa possibilidade de aprimorar esses modos, assim como promover a aprendizagem em relação ao manejo do tratamento. É o contrapeso nos atuais padrões de cuidado, é criar espaços e transcender saberes e práticas para o melhor nível de cuidado dentro do modelo assistencial.

\section{Consideraçõesfinais}

Os resultados permitem considerar que, para a eficácia da tecnologia e efetividade do cuidado no trabalho com grupos, é preciso ampliar a reflexão sobre essa temática e a prática desempenhada.

O ensaio de um novo saber-fazer grupo, utilizando-se tecnologias que possibilitam atitudes 
humanizadoras tanto na perspectiva dos coordenadores quanto dos clientes, aponta que o olhar para a pessoa com diabetes e hipertensão vai além das vigilâncias relacionadas ao uso dos medicamentos. Há indícios queevidenciam avanço na atenção prestada à clientela, no sentido de voltar-se para aspectos que influenciam o tratamento eo controle, demodo a conhecer o cotidiano dessa, as dificuldades e facilidades em seu contexto de vida, a sua cultura.

Tanto para os enfermei ros desteestudo quanto para os diferentes profissionais coordenadores de grupos da Saúde da Família, a questão é que existemuito a ser feito no que diz respeito ao cuidado. 0 primeiro passo éa sensibilização para a necessidade de se respeitar as diferentes dimensões socioculturais que formatam a visão de mundo de cada pessoa. Não obstante, o cuidado se efetivará na cumplicidade entre profissional de saúdee cliente, utilizando-se do conhecimento popular e científico e da interatividade com o outro.

\section{Colaboradores}

M TO. Fernandes participou do delineamento do estudo, da coleta e da análise dos dados e foi a redatora principal do artigo. LB Silva participou do delineamento do estudo, da coleta e análise dos dados e da redação do trabalho. SM Soares participou como orientadora da dissertação de mestrado, colaborou no delineamento do estudo, análise dos dados e revisão crítica final do artigo.
O bserva-se, ainda, um aspecto importante e universal que é a carência e baixa utilização de mídias como vídeos e filmes nesses grupos. Além da dificuldade, na prática, de abordar o aspecto relacional e dialógico.

Assim, considera-se com este estudo que a tecnologia deve trazer consigo al go que seja interessantee atrativo para maior efetividade do cuidado na perspectiva de grupo. Ao mesmo tempo, deve facilitar a escuta, o acolhimento, a integração e o vínculo, considerando crenças e valores e a disseminação do conhecimento bilateral de culturas e do cuidar. Quando os sujeitos envolvidos desenvolvem autonomia, épossível que, depois de todo esse processo, reconheçam sua cultura, saberes, práticas de cuidado, assim como a cultura e o conhecimento profissional, possibilitando escolhas de modo mais consciente, pela melhor forma de se cuidar, o que se observa ser a proposta implícita desses grupos de pessoas com diabetesmellitus ehipertensão arterial, ainda não desvelada pelos atores envolvidos. 
1. M erhy EE. Saúde: a cartografia do trabalho vivo. São Paulo: Hucitec; 2002.

2. Franco $T B$, Magalhães Júnior HM M. Integralidade na assistência à saúde: a organização das linhas do cuidado. In: Mehry EE, organizador. 0 trabalho em saúde: olhando e experienciando o SUS no cotidiano. São Paulo: Hucitec; 2003. p. 125-134.

3. Fernandes MTO, Loés RR. 0 consumo de medicamentos como indicador da qualidade da atenção à saúde da população acima de 60 anos [monografia]. Belo Horizonte (MG): Universidade Federal de M inas Gerais; 2003.

4. Prefeitura de Belo Horizonte. Secretaria Municipal de Saúde. BH-Vida: Saúde Integral. Diretrizes para 0 avanço e articulação do processo assistencial na SM SA para o período 2003-2004. 3a ed. Belo Horizonte: Prefeitura de Belo Horizonte; 2003.

5. Prefeitura de Belo Horizonte. Secretaria Municipal de Saúde. Saúde - Informação para Atenção Básica Consolidados de Famílias - Relatórios de Produção das Equipes. [site da Internet] 2005 [acessado 2006 fev 23]. Disponível em: http://www.pbh.gov.br/ smsa/intranet

6. M unari DB, Soares SM, Godoy MTH, Esperidião E. O uso do grupo na assistência em saúde: análise crítica e possibilidades. In: Santos I, David HSL, Silva D, Tavares CM M, organizadores. Enfermagem e campos de práticas em saúde coletiva: realidade, questões e soluções. Rio de Janeiro: Atheneu; 2008. p. 140-147.

7. Soares SM, Ferraz AF. Grupos operativos de aprendizagem nos serviços de saúde: sistematização de fundamentos e metodologias. Esc Anna Nery R Enferm 2007; 11(1): 52-57.

8. Polit DF, Hungler BP. Pesquisa e análise qualitativa. In: Polit DF, Hungler BP, organizadores. Fundamentos da pesquisa em enfermagem. $3^{a}$ ed. Porto Alegre: Artes Médicas; 1995. p. 268-288.

9. Bardin L. Análise de conteúdo. Lisboa: Edições 70; 1977.

10. Brasil. Ministério da Saúde. Conselho Nacional de Saúde. Comitê Nacional de Ética em Pesquisa em Seres Humanos. Resolução $n^{\circ} 196$ de 10 de outubro de 1996: diretrizes e normas regulamentadoras de pesquisas envolvendo seres humanos. Diário Oficial da U nião 1996; 16 out.

11. Santos AM, Assis M M A, Rodrigues AAAO, Nascimento MAA, Jorge MSB. Linhas de tensões no processo de acolhimento das equipes de saúde bucal do Programa Saúde da Família: o caso de Alagoinhas, Bahia, Brasil. Cad Saude Publica 2007; 23(1):75-85.

12. Brasil. Ministério da Saúde. Saúde da Família: uma estratégia para a reorientação do modelo assistencial. Brasília: M inistério da Saúde; 1997.

13. Pichón-Rivière E. $O$ processo grupal. $6^{a}$ ed. São PauIo: Martins Fontes; 1998.

14. Dall'Agnol CM, Resta DG, Zanatta E, Schrank G, $M$ affacciolli R. $O$ trabalho com grupos como instância de aprendizagem em saúde. Rev Gaucha de Enferm 2007; 28(1):21-26.
15. Campos GW. Considerações sobre a arte e a ciência da mudança: revolução das coisas e a reforma das pessoas. 0 caso da saúde. In: Cecílio LCO, organizador. Inventando a mudança na saúde. $2^{2} \mathrm{a}$ ed. São Paulo: Hucitec; 1997. p. 29-87.

16. Stefanelli MC, Carvalho EC, Arantes EC. A comunicação nos diferentes contextos da Enfermagem. Barueri: M anole; 2005.

17. Idáñez MJA. Como animar um grupo: princípios básicos e técnicas. Petrópolis: Vozes; 2004.

18. Bleger J. Temas de Psicologia: entrevista e grupos. $2^{\text {a }}$ ed. São Paulo: M artins Fontes; 1998.

19. Mailhiot GB. Dinâmica e gênese dos grupos: atualidade das descobertas de Kurt Lewin. $5^{a}$ ed. São Paulo: Duas Cidades; 1981.

20. Oriá $M O B$, M oraes LMP, Victor JF. A comunicação como instrumento do enfermeiro para o cuidado emocional do cliente hospitalizado. Rev Eletr Enferm 2004; 6(2):292-297.

21. Wachelke JFR, Natividade JC, Andrade AL. Construção e utilização de técnicas em dinâmicas de grupos. Psicol Argum 2005; 23(42):31-39.

22. Andaló CSA. 0 papel de coordenador de grupos. Psicol USP 2001; 12(1):135-152.

23. M inicucci $A$. Técnicas do trabalho de grupo. São PauIo: Atlas; 1992

24. M ota KAM B, M unari DB. Um olhar para a dinâmica do coordenador de grupos. Rev Eletr Enferm 2006; 8(1):150-161.

25. Andreola BA. Dinâmica de grupo: jogo da vida e didática do futuro. 17ạ ed. Petrópolis: Vozes; 1999.

26. Zimerman DE. Fundamentos básicos das grupoterapias. 2a ed. Porto Alegre: Artes M édicas; 2000.

27. Trentini M, Tomasi NS, Polak YNS. Prática educativa na promoção da saúde com grupo de pessoas hipertensas. Cogitare Enferm 1996; 1(2):19-24.

28. Chiaravalloti VB, M orais MS, Neto FC, Conversani DT, Fiorin AM, Barbosa AAC, Ferraz AA. Avaliação sobre a adesão às práticas preventivas do dengue: o caso de Catanduva, São Paulo, Brasil. Cad Saude Publica 2002; 18(5):1321-1329.

29. Silva CP, Dias MSA; Rodrigues AB. Práxis educativa em saúde dos enfermeiros da Estratégia Saúde da Família. Cien Saude Colet 2007; 14(supl. 1):14531462.

30. Moura ERF, Sousa RA. Educação em saúde reprodutiva: proposta ou realidade do Programa Saúde da Família? Cad Saude Publica 2002; 18(6):1809-1811.

31. Baraúna T. Criatividade: uma necessidade para a enfermagem. N ursing 2001; 3(6):8-9.

32. Anzieu D. 0 grupo e 0 inconsciente. São Paulo: Casa do Psicólogo; 1983.

33. Cardoso MAR, Moraes ZB, Velôso IBP, Silva RD. Ações educativas vivenciadas junto a pacientes idosos: relato de experiência. Sitientibus 2005; 33:41-51.

34. Almeida SP. A vivência no grupo: a experiência para a pessoa diabética [dissertação]. Belo Horizonte (MG): Universidade Federal de M inas Gerais; 2006. 
35. Câmara M FB, Damásio VF, Munari DB. Vivenciando os desafios do trabalho em grupo. Rev Eletr Enferm [periódico na Internet]. 1999 [acessado 2007 dez 5]; 1(1):[cerca de 8 p.]. Disponível em: http:// www.fen.ufg.br/ revista/revistal_1/09.htm

36. Fortuna CM, M ishima SM, M atumoto S, Pereira MJB. $O$ trabalho de equipe no Programa de Saúde da Família: reflexões a partir de conceitos do processo grupal e de grupos operativos. Rev. LatinoAm Enfermagem 2005; 13(2):262-268.

Artigo apresentado em 11/08/2008

Aprovado em 07/01/2009

Versão final apresentada em 11/01/2009 